\title{
New Hope of Funding for the Environmental Movement
}

At least in times of peace, there can rarely if ever have been a more difficult period than the present for funding worthy enterprises that cannot promise rapid returns of a practical and economic nature. Yet apart from direct pollutional clean-up, most activities undertaken on behalf of the environment of Man and Nature belong to this lagging, non-promising category which is now widely 'out of luck'. Due preparation for effective action in the environmental field is commonly more difficult for the holders of purse-strings to comprehend than is direct action itself, and when we have to go yet farther back in the sequence that starts with ideas and ends up in effective practical application, these problems are further aggravated-often out of all bounds as others emerge. Conferences and publications come somewhere between the extremes of theoretical ideas and practical action, as also do most institutions. The environmental movement needs them all and is in dire straits through lack of funding. As a result, journals have died or been curtailed, promising programmes have been discontinued or never started, conferences have been cancelled or postponed, and some of the worthiest institutions are in a state of chronic crisis or actually threatened with closure.

Even worse, commonly but not universally, is the situation of research-the seemingly everlasting sine qua non of advance towards a better world. For although it may be said with some truth that we now have the necessary knowledge to take most of the actions that are becoming more and more necessary on behalf of the environment of Man and Nature, we shall probably never have enough to allow widespread apathy, inter alia because circumstances and conditions change eternally. This is especially the case where life is involved, as it is very deeply in almost all environmental considerations. So a wide range of research must go on-be it pure and basic or applied and operation-oriented, and whether or not one can make this distinction. In all these circumstances it is particularly unfortunate that there are often no funds to start what could be quite vital research projects, much less to prosecute them through to fruition.

To be sure, when we were young we did not expect to be paid to undertake 'pure' research or even to be given our expenses: we simply did it. But those were different days whole decades ago-when, for example, modest payment from a national museum in return for collections made was sufficient, with perhaps a little parental assistance or some travelbook royalties, for a summer-long research expedition to Greenland or Spitsbergen or even farther afield. Now is the time of shortages and suffering, when many dedicated individuals and organizations have to find the means to continue on a shoestring or else fold up. Often they barely manage to survive through sheer persistence, exhausted by wasteful seeking of funds and struggles to make up for deficitory budgets.

In all these circumstances of difficulty and even disaster-partly due to inflation and other economic problems, partly due to the fact that environmental matters are still often little understood or appreciated except as pollutional or other nuisances, and partly for yet other reasons including opposition to action on grounds of cost or by vested intereststhe environmental movement is making only limited progress in some connections and is even in jeopardy in others. Consequently a recent news item is to be especially welcomed as portending hope. It emanates from United Nations circles in New York and, according to the International Herald Tribune of 26 October 1976, announces: 'Saudi Arabia will propose to the General Assembly a one-cent-per-barrel tax on oil produced throughout the world, to finance the United Nations Environment Program [UNEP]. The tax would bring an annual income of between $\$ 750$ million and \$1 [thousand million]. Saudi Arabia's Ambassador, Jamil Baroody, said that he would introduce the proposal in the Assembly's Economic Committee. The tax, he said, would be collected by the oil-producing countries from oil companies.'

Whereas one would have thought that the small burden of this levy should be shared by the producing countries themselves in their affluence, its totality constitutes a fine wind of hope. For with it UNEP ought to be able to take its rightful place as the solid funding source of the environmental movement throughout the world and not merely of bits of it (and often, latterly, in a very limiting way owing to lack of funds). Better still, we would think, would be if OPEC or some other world body could distribute a substantial part of these ardently-to-be-hoped-for funds directly to worthy, needful, and untied, outfits such as SCOPE, IUCN, and some others. For such small operations as those of our own Foundation for Environmental Conservation, a mere fraction of a thousandth part of this proposed levy would enable us, with our modest overheads already supplied, to ensure consummation of a number of projects of the widest significancequite apart from extending this Journal in the manner it deserves, continuing with more specialized International Conferences on Environmental Future, continuing a free international environmental consultancy and including a sub-agency to list ahead (and report after) all pertinent conferences and meetings in the environmental field (sensu latissimo), and taking a number of other actions on behalf ultimately of the environment that in some cases have long been planned and only need funding. Other proposals are brought to us practically all the time, some of them being both admirable and urgent; already we have adopted a project for a Multilingual Systematic Glossary of Environmental Terms and are considering one for a World Heritage series of books.

In a spirit of optimism a correspondent has pointed out (C.D.W. Savage, in litt. 8 Nov. 1976): 'It is to be hoped that such much-needed support for international conservation would not be restricted to UNEP per se as there are many vital and integral parts [of the environmental/conservation movement] which are starved for funds, and overwhelming support for one could lead to burgeoning bureaucracy and inefficiency...' Meanwhile we are informed by a leading economist in the United Nations complex that this Saudi Arabian proposal, which is fundamentally a system of indirect (turnover) taxation, seems to be a departure for the international community (including the United Nations) and as such is 'extremely interesting'. But we wonder privately how the United Nations will react to this initiative if it is directed at only one member of its 'family': would not the best solution lie in multilateral direct funding of other worthy factions of the environmental movement? To the extent that implementation of such a suggestion that not everything should go to (or even through) UNEP would reduce the United Nations take, it would also reduce this foreseeable dilemma. But in any case the proposal of Saudi Arabia is to be most warmely welcomed as a possible means of substantially bridging the cruel gap between what needs to be done for the environment-indeed increasingly as time goes on-and what it is possible to find funding to do in these days of financial stringency and widespread doubts about the future. 